\title{
Expression of WTH3 in breast cancer tissue and the effects on the biological behavior of breast cancer cells
}

\author{
LIN GAN ${ }^{1}$, GUOQING ZUO ${ }^{2}$, TING WANG ${ }^{1}$, JIE MIN $^{1}$, YADONG WANG ${ }^{1}$, YONGYUE WANG ${ }^{1}$ and GANG LV ${ }^{1}$ \\ Departments of ${ }^{1}$ Mammary Gland and Thyroid Gland, and ${ }^{2}$ Gastroenterology, Chongqing Hospital of \\ Traditional Chinese Medicine, Chongqing 404100, P.R. China
}

Received July 12, 2014; Accepted February 11, 2015

DOI: 10.3892/etm.2015.2458

\begin{abstract}
The aim of the present study was to investigate the expression of WTH3 in tumor and normal breast tissue. The mRNA and protein expression levels of WTH3 were detected using reverse transcription quantitative polymerase chain reaction and western blot analysis, respectively. In addition, matrix metalloproteinase (MMP)-2 protein expression was measured. The effect of WTH3 expression on the proliferation activity of breast cancer cells was detected using a Cell Counting Kit-8 assay. Furthermore, the effects of WTH3 on the invasion and migration ability of the breast cancer cells was investigated. The results revealed that WTH3 was able to significantly inhibit the proliferation of the MCF-7 and MDA-MB-231 breast cancer cell lines. In addition, the invasion and migration assay demonstrated that WTH3 was able to inhibit the invasion and migration of breast cancer cells. Western blot analysis revealed that increased expression of WTH3 resulted in decreased expression levels of MMP-2, which has an important function in the metastasis of cancer cells. In conclusion, WTH3 expression differed between the tumor and normal breast tissues. WTH3 was able to inhibit the proliferation of breast cancer cells and decrease their invasion ability. Thus, WTH3 may be a promising target for breast cancer therapy in the future.
\end{abstract}

\section{Introduction}

Breast cancer is a common malignant tumor with a high mortality rate in females. According to World Health Organization statistics, $\sim 1,500,000$ cases occur each year worldwide, with 200,000 new cases arising annually in China alone (1). There has been major development in the research of breast cancer pathogenesis, particularly in the field of onco-

Correspondence to: Dr Gang Lv, Department of Mammary Gland and Thyroid Gland, Chongqing Hospital of Traditional Chinese Medicine, 6 Panxiqizhi Road, Jiangbei, Chongqing 404100, P.R. China

E-mail: 1v_gang_1969@163.com

Key words: WTH3, breast cancer, biological behavior gene protein expression, with the identification of cyclin D1, p53 and Rab (2-4). These proteins have varying expression levels in tumor and normal breast tissues, and are able to cause a variety of changes in the biological behavior of cells (2-4).

WTH3 is a gene that was identified during early studies of multiple drug resistance (5). In a previous study involving drug-resistant MCF-7/AdrR cells, the promotor of the WTH3 gene was hypermethylated and the expression of WTH3 was downregulated (6). WTH3 belongs to the Rab6 superfamily, whose expression product can bind to GTP. In contrast to Rab6s, which is located on the Golgi apparatus, WTH3 is primarily distributed in the cytoplasm and is unable to bind to the cytomembrane to perform its biological functions. According to the results of previous studies, WTH3 has an effect on the drug resistance of breast cancer cells and has a bidirectional regulatory function on certain cellular behaviors $(7,8)$.

In the present study, the expression of WTH3 in breast cancer tissue was detected. In addition, an MCF-7 and MDA-MB-231 in vitro cell model was used to investigate the possible mechanisms underlying the effects of WTH3 on breast cancer.

\section{Materials and methods}

Clinical specimens and cell lines. Breast cancer tissue specimens were collected from five patients aged between 55 and 60 years old at the Chongqing Hospital of Traditional Chinese Medicine (Chongqing, China). Written informed patient consent was obtained from the patients and the study was approved by the ethics committee of Chongqing Hospital of Traditional Chinese Medicine. Human breast cancer cell lines, MCF-7 and MDA-MB-231, were purchased from the Cell Resource Center of the Shanghai Institutes for Biological Sciences at the Chinese Academy of Sciences (Shanghai, China). MDA-MB-231-WTH3 (WTH3 overexpression) and MCF-7 WTH3-/- (WTH3 knockout) cell lines were previously established by the current research group and maintained in our laboratory. Cells were cultured in Dulbecco's modified Eagle's medium (DMEM; Gibco Life Technologies, Beijing, China) supplemented with $10 \%$ (v/v) heat-inactivated fetal bovine serum (FBS; Gibco) and penicillin-streptomycin (100 IU/ml-100 lg/ml; Gibco) at $37^{\circ} \mathrm{C}$ in a humid atmosphere (5\% $\mathrm{CO}_{2}$ to $95 \%$ air). The cells were harvested by brief incu- 
A

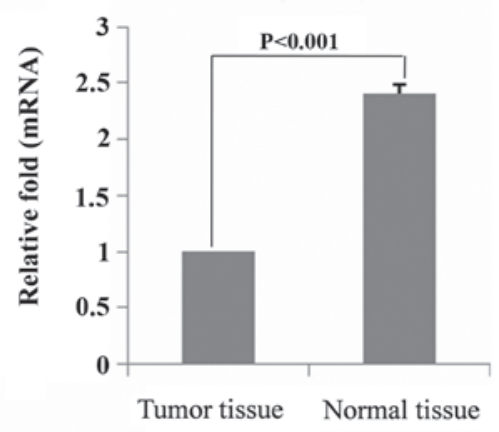

C

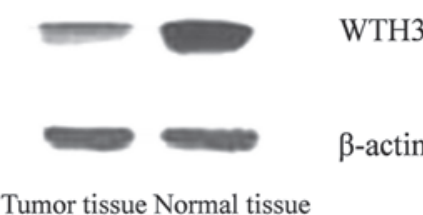

B
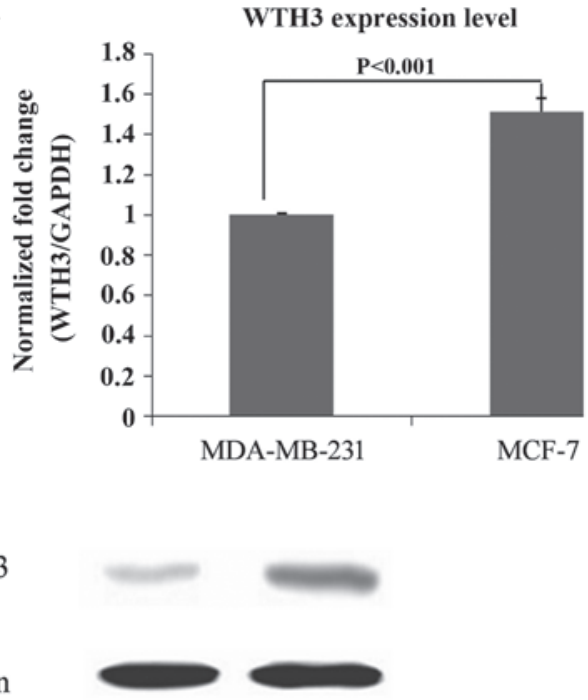

MDA-MB-231 MCF-7

Figure 1. Expression levels of WTH3. mRNA expression levels of WTH3 in (A) tumor and normal breast tissue and (B) MCA-MB-231 and MCF-7 cell lines. (C) Protein expression levels of WTH3.

bation with $0.25 \%$ Tryptase (Sigma-Aldrich, St. Louis, MO, USA).

Reverse transcription quantitative polymerase chain reaction $(P C R)$. Total RNA was extracted using an RNeasy kit (Sangon Biotech, Shanghai, China). Reverse transcription was conducted with $0.5 \mu \mathrm{g}$ extracted RNA using the First Strand cDNA Synthesis kit (Beyotime Institute of Biotechnology, Haimen, China). PCR primer pairs were as follows: WTH3 sense, 5'-GATGGAACAATCGGGCTTCG-3' and antisense, 5'-GCTGCTACACGTCGAAAGAGC-3'; $\beta$-actin sense, 5'-GACGACATGGAGAAGATCTGG-3' and antisense, 5'-ATCGGGCAGCTCGTAGCTCTTC-3'), where $\beta$-actin was used as an internal control. The reaction was performed at $95^{\circ} \mathrm{C}$ for $5 \mathrm{~min}$, followed by 35 cycles at $95^{\circ} \mathrm{C}$ for $15 \mathrm{sec}, 60^{\circ} \mathrm{C}$ for $30 \mathrm{sec}$ and $72^{\circ} \mathrm{C}$ for $30 \mathrm{sec}$, and finally $72^{\circ} \mathrm{C}$ for $10 \mathrm{~min}$. PCR products were run on $2.0 \%$ agarose gels containing $0.5 \mathrm{lg} / \mathrm{ml}$ ethidium bromide and photographed under a UV transilluminator; relative light intensities were analyzed using AlphaEaseFC software.

Western blot analysis. Western blot analysis was used to evaluate the protein expression levels of WTH3 and matrix metalloproteinase (MMP)-2 in breast tumor tissue and cancer cell lines in vitro. The tumor tissue was dispersed mechanically with phosphate-buffered saline (PBS) and the supernatant was collected, from which the protein concentration was determined using a bicinchoninic acid protein assay kit (Beyotime). The cancer cells were harvested and the cell lysates $(30 \mu \mathrm{g}$ protein/lane) were fractionated by $10 \%$ SDS-PAGE. The protein was electrotransferred onto polyvinylidene fluoride membranes (EMD Millipore, Billerica, CA, USA), and the protein levels were determined using the dilutions of the primary antibodies overnight at $4^{\circ} \mathrm{C}$, including a mouse polyclonal anti-WTH-3 (1:2,500, \#ab168296; Abcam, Cambridge, MA, USA) and monoclonal anti-MMP-2 (1:800, \#sc-13595;
Santa Cruz Biotechnology, Inc., Dallas, TX, USA) antibodies. The primary antibodies were washed in $0.05 \%$ Tween-20/PBS, then incubated with a goat anti-mouse horseradish peroxidase (HRP)-conjugated IgG secondary antibody for $40 \mathrm{~min}$ at room temperature (1:800, ZDR-5307; ZSGB-BIO, Bejing, China). The bound antibodies were visualized using an enhanced chemiluminescence reagent (Amersham Pharmacia Biotech, Piscataway, NJ, USA) and quantified using a LAS 4000 mini chemiluminescence imaging system (GE Healthcare, Little Chalfont, UK).

Cell Counting Kit-8 (CCK-8) assay for cell proliferation activity. Breast cancer cells at the logarithmic growth phase were seeded into 96 -well plates $\left(2 \times 10^{3}\right.$ cells/well). The cells were incubated at $37^{\circ} \mathrm{C}$ for $18-24 \mathrm{~h}$ for adherence, after which incubation continued for 1-7 days to form a sigmoid growth curve. Cell proliferation activity was detected by adding $10 \mu \mathrm{l}$ CCK-8 solution to each well, and the light absorbance of the solution [optical density (OD)] was measured at $450 \mathrm{~nm}$ using a microplate reader (Molecular Devices LLC, Sunnyvale, CA, USA). A cell growth curve was generated with time as the abscissa and $\mathrm{OD}_{450}$ as ordinates.

Invasion and migration assay. A 24-well Transwell chamber (Corning, Inc., Corning, NY, USA) was used to evaluate the motility and invasive ability of the carcinoma cells. The upper surfaces of the polycarbonate filters with $8 \mu \mathrm{m}$ pores were coated with $100 \mu \mathrm{g}$ Matrigel (Corning, Inc.). The lower chambers were filled with $800 \mu 1$ DMEM with 10\% FBS. A cell suspension $\left(2.5 \times 10^{4}\right.$ cells $\left./ 100 \mu \mathrm{l}\right)$ was placed in the upper chambers and incubated at $37^{\circ} \mathrm{C}$ in a $\mathrm{CO}_{2}$ incubator. Following incubation, any cancer cells remaining on the upper surface of the filters were removed by wiping with cotton swabs. The cells that had migrated to the lower surface were stained with Giemsa stain (Sigma-Aldrich). Five fields of vision were randomly selected and the number of cells on the lower surface 


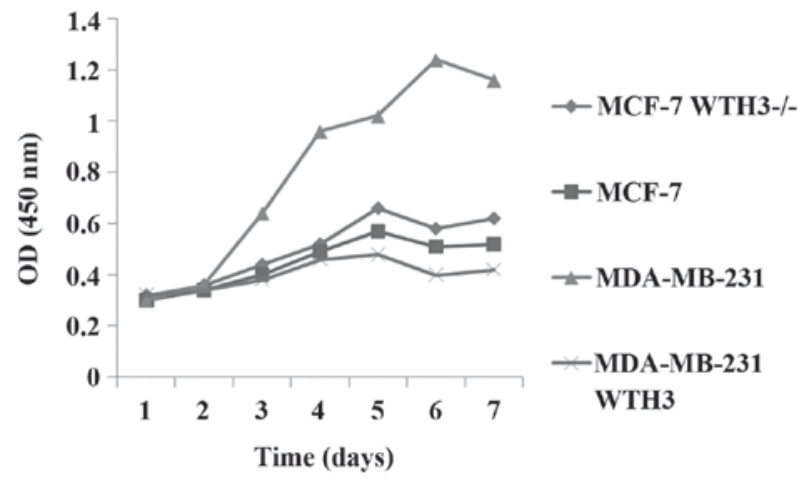

Figure 2. Effect of WTH3 on the proliferation of the various breast cancer cell lines. From day 2, the proliferation activity of MDA-MB-231 WTH3 cells with overexpression of WTH3 was markedly decreased $(\mathrm{P}<0.05)$. Compared with the original MCF-7 cells, the WTH3 knockout cell line, MCF-7 WTH3-/-, showed improved proliferation activity $(\mathrm{P}<0.05)$. OD, optical density.
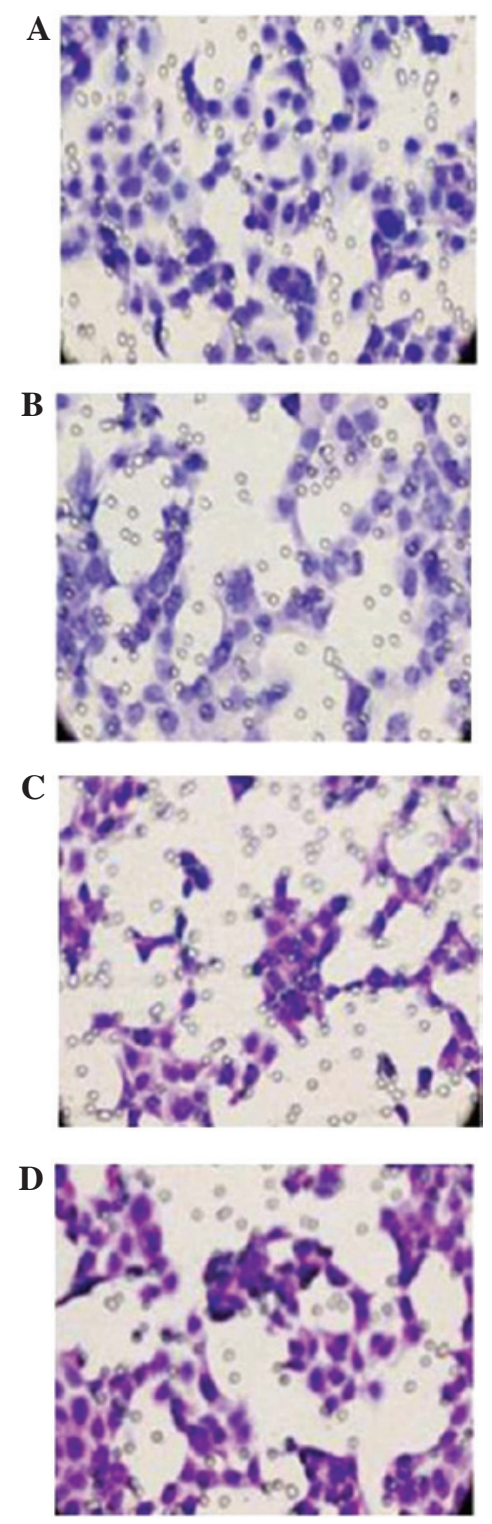

Figure 3. Effect of WTH3 on breast cancer cell invasion and migration in (A) MDA-MB-231, (B) MDA-MB-231-WTH3, (C) MCF-7 and (D) MCF-7 WTH3-/-cell lines. Cancercells in various groups were placed on Matrigel-coated filters and incubated for $24 \mathrm{~h}$. The number of cells passing through the filters was counted after staining with Giemsa (magnification, x400).

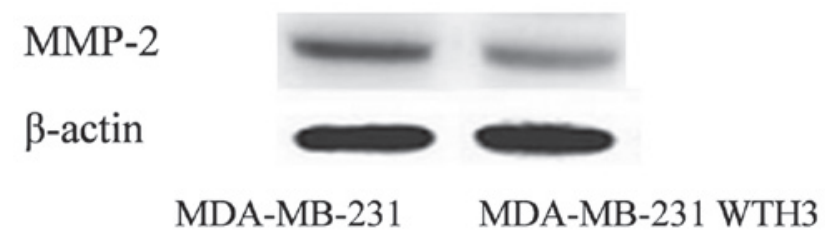

\section{MMP-2 \\ $\beta$-actin}

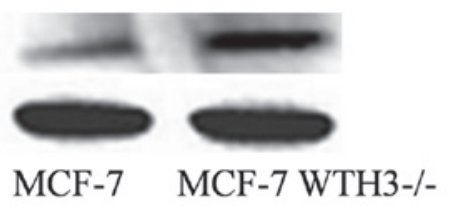

Figure 4. Effect of WTH3 on the protein expression of MMP-2 in breast cancer cells. MMP, matrix metalloproteinase.

of the filters were counted under an Olympus microscope (Olympus Corporation, Tokyo, Japan) at a magnification of x400.

Statistical analysis. Data are presented as the mean \pm standard deviation and were analyzed using SPSS 13.0 software (SPSS, Inc., Chicago, IL, USA). Statistical differences between groups were analyzed by one-way analysis of variance and Fisher's least significant difference $t$-test, where $\mathrm{P}<0.05$ was considered to indicate a statistically significant difference.

\section{Results}

Expression of WTH3 in breast cancer tissue. Compared with the normal breast tissue, the expression of WTH3 in breast tumor tissue was downregulated at an mRNA and protein level (Fig. 1A; $\mathrm{P}<0.001$ ). The metastatic ability of MDA-MB-231 cells is higher compared with MCF-7 cells, and the mRNA expression of WTH3 in the MDA-MB-231 cells was lower compared with the MCF-7 cells (Fig. 1B; P<0.001). As shown in Fig. 1C, the expression of WTH3 in normal tissue was higher compared with tumor tissue, while in the same time in MDA-MB-31 cells with high metastatic ability the expression of WTH3 was reduced compared with MCF-7 cells (Fig. 1B; P<0.001).

Measurement of cell proliferation capacity. As shown in Fig. 2, the proliferation ability of MDA-MB-231 cells was significantly stronger compared with that of MCF-7 cells. From day 2, the proliferation activity of MDA-MB-231 WTH3 cells with overexpression of WTH3 was markedly decreased $(\mathrm{P}<0.05)$. Compared with the original MCF-7 cells, the WTH3 knockout cell line, MCF-7 WTH3-/-, showed improved proliferation activity $(\mathrm{P}<0.05)$

Inhibition of breast cancer cell invasion and migration. The inhibitory effect of WTH3 on the invasion and migration of breast carcinoma cells was examined using an invasion assay with Matrigel-coated filters. The results showed that MDA-MB-231 cells had a higher invasive ability than MCF-7 cells. Furthermore, the invasive ability of the WTH3 knockout (MCF-7 WTH3-/-) cell line was increased and WTH3 overexpression cell line (MDA-MB-231 WTH3) were decreased $(\mathrm{P}<0.01)$. As shown in Fig. 3, WTH3 inhibited the invasion and migration of breast cancer cells. 
Effect of WTH3 on the expression of MMP-2 in breast cancer cells. Compared with the original MDA-MB-231 cell line, the expression of MMP-2 in the MDA-MB-231 WTH3 cell line was decreased $(\mathrm{P}<0.01)$. MMP-2 expression in the MCF-7 WTH3-/- cells was higher compared with the MCF-7 cell line $(\mathrm{P}<0.001)$. The expression levels of WTH3 and MMP-2 were shown to have a negative association (Fig. 4).

\section{Discussion}

Previous studies have demonstrated that mutations in the BRCA1, BRCA2 and P53 genes can partially explain the pathogenesis of breast cancer $(8,9)$. However, the incidence of breast cancer may also be associated with other unknown genes, and studies have suggested that the tumorigenesis and metastasis of certain cancer types is strongly associated with the loss of Rab gene function (10-12). The Rab family is the largest subfamily of the small GTP-binding protein Ras superfamily, which plays a regulatory role as a GTP-dependent molecular switch at different stages of vesicular transport (13). The life processes of eukaryotic cells are accompanied by protein transport between organelles; this intracellular protein transportation is dependent on vesicular transport. Rab proteins are key regulatory factors in the process of intracellular vesicle transport $(14,15)$. Mutations in the Rab gene or abnormal expression may cause disorder in the process of vesicle transport. If proteins are unable to be accurately transported to their destination, a variety of diseases may arise, including tumors (3).

WTH3 is a newly identified member of the Ras family homologous to RAB6/RAB6C encoding small G proteins consisting of 254 amino acids, which protein is highly homologous to the protein of 208 amino acids encoded by RAB6/RAB6C $(16,17)$. Differences between the proteins include substitutions at amino acids 19 and 22 in WTH3, and an extended sequence of 46 amino acids without cysteine in the carboxy-terminal of WTH3. Therefore, WTH3 does not undergo modification following translation and is unable to bind to the membrane to exert a biological function (18-20). Since WTH3 was identified during the study of tumor drug resistance, a number of studies have investigated the methylation and transcriptional regulation of the gene $(5,21)$. In the present study, the expression level of WTH3 in human breast cancer tissue and breast cancer cell lines was investigated and an abnormal expression was observed. Using the previously constructed cell lines, the results of the present study indicated that WTH3 was able to inhibit certain biological behaviors of the breast cancer cells, including cell proliferation, migration and invasion. WTH3 may inhibit cell proliferation through the activation of one or more tumor suppressor genes, including the P53 transcription factor, or negative regulation of the WT transcription factor and DNA repair factors BRCA1 and BRCA2, all of which can be effective in promoting apoptosis and the inhibition of tumor cell growth $(21,22)$. However, the exact mechanism underlying the effects of WTH3 requires further study.

Tumor invasion and metastasis is a multi-step cascade amplification process. The tumor cells leave the original lesions, pass through the extracellular matrix and basement membrane, migrate to the site of vascular invasion, adhere to the vascular endothelium, enter the circulatory system and migrate through blood vessels into the extracellular matrix to form metastases (23). During the entire process of tumor invasion and metastasis, the degradation of the basement membrane and extracellular matrix is important. MMPs are enzymes that are essential for this process. MMPs play a role in the degradation of the extracellular matrix by promoting epithelial-mesenchymal transition, promoting the activation of growth factors, their receptors and angiogenesis, and facilitating tumor invasion and metastasis (24-27). Previous studies revealed that the expression of MMP-2 in breast cancer tissue is higher compared with normal breast tissue. Such abnormal expression can promote tumor growth, invasion and metastasis by increasing the vascular permeability of cancer cells and the degradation of the extracellular matrix $(28,29)$.

The results of the current study revealed that the breast cancer cell line with high invasive capacity, MDA-MB-231 WTH3, had a lower invasive ability following elevation of WTH3 expression. In addition, the number of invasive and migratory cells was significantly decreased, which consequently inhibited the malignancy of the cancer cells. However, in the MCF-7 WTH3-/- cell line, the invasion and metastatic ability of the cells was markedly increased as a result of WTH3 gene knockout. Further investigation using the four cell lines demonstrated a negative association between MMP-2 and WTH3 expression, indicating that the inhibitory metastatic mechanism of WTH3 may be associated with its inhibitory effects on MMP-2 expression.

In summary, the expression of WTH3 differs between human breast cancer tissue and normal breast tissue. Furthermore, WTH3 can inhibit tumor proliferation, invasion and metastasis; thus, WTH3 is an important and promising therapeutic target for breast cancer therapy.

\section{Acknowledgements}

This study was supported by a grant from the National Natural Science Foundation of China (no. 81271598).

\section{References}

1. Siegel R, Naishadham D and Jemal A: Cancer statistics, 2013. CA Cancer J Clin 63: 11-30, 2013.

2. Saitoh M, Ohmichi M, Takahashi K, Kawagoe J, Ohta T, Doshida M, Takahashi T, Igarashi H, Mori-Abe A, Du B, Tsutsumi S and Kurachi H: Medroxyprogesterone acetate induces cell proliferation through up-regulation of cyclin D1 expression via phosphatidylinositol 3-kinase/Akt/nuclear factor-kappaB cascade in human breast cancer cells. Endocrinology 146: 4917-4925, 2005.

3. Cheng KW, Lahad JP, Kuo WL, Lapuk A, Yamada K, Auersperg N, Liu J, Smith-McCune K, Lu KH, Fishman D, Gray JW and Mills GB: The RAB25 small GTPase determines aggressiveness of ovarian and breast cancers. Nat Med 10: $1251-1256,2004$

4. Dookeran KA, Dignam JJ, Ferrer K, Sekosan M, McCaskill-Stevens W and Gehlert S: p53 as a marker of prognosis in African-American women with breast cancer. Ann Surg Oncol 17: 1398-1405, 2010.

5. Tian K, Wang Y, Huang Y, Sun B, Li Y and Haopeng Xu: Methylation of WTH3, a possible drug resistant gene, inhibits p53 regulated expression. BMC Cancer 8: 327, 2008.

6. Shan J, Mason JM, Yuan L, Barcia M, Porti D, Calabro A, Budman D, Vinciguerra V and Xu H: Rab6c, a new member of the rab gene family, is involved in drug resistance in MCF7/AdrR cells. Gene 257: 67-75, 2000. 
7. Shan J and Yuan L: WTH3, a new member of the Rab6 gene family, and multidrug resistance. Biochim Biophys Acta 1589 112-123, 2002.

8. Abdel-Fatah TM, Powe DG, Agboola J, et al: The biological, clinical and prognostic implications of p53 transcriptional pathways in breast cancers. J Pathol 220: 419-434, 2010.

9. van Beers EH, van Welsem T, Wessels LF, et al: Comparative genomic hybridization profiles in human BRCA1 and BRCA2 breast tumors highlight differential sets of genomic aberrations. Cancer Res 65: 822-827, 2005.

10. Culine S, Honoré N, Closson V, Lang P, Bertoglio J, Tavitian A and Olofsson B: A possible role for the Ras-related Rab2 protein in the immunological events associated with hematological malignancies. Nouv Rev Fr Hematol 35: 41-44, 1993.

11. He H, Dai F, Yu L, She X, Zhao Y, Jiang J, Chen X and Zhao S: Identification and characterization of nine novel human small GTPases showing variable expressions in liver cancer tissues. Gene Expr 10: 231-242, 2002.

12. Amillet JM, Ferbus D, Real FX, Antony C, Muleris M, Gress TM and Goubin G: Characterization of human Rab20 overexpressed in exocrine pancreatic carcinoma. Hum Pathol 37: 256-263, 2006.

13. Pereira-Leal JB and Seabra MC: The mammalian Rab family of small GTPases: definition of family and subfamily sequence motifs suggests a mechanism for functional specificity in the Ras superfamily. J Mol Biol 301: 1077-1087, 2000.

14. Tuvim MJ, Adachi R, Hoffenberg S and Dickey BF: Traffic control: Rab GTPases and the regulation of interorganellar transport. News Physiol Sci 16: 56-61, 2001.

15. Calero M, Chen CZ,Zhu W, et al: Dual prenylation is required for Rab protein localization and function. Mol Biol Cell 14: 1852-1867, 2003.

16. Goud B and Zahraoui A: Small GTP-binding protein associated with Golgi cisternae. Nature 345: 553-556, 1990.

17. Echard A, Opdam FJ, de Leeuw HJ, et al: Alternative splicing of the human Rab6A gene generates two close but functionally different isoforms. Mol Biol Cell 11: 3819-3833, 2000.

18. Morikawa RK, Aoki J, Kano F, et al: Intracellular phospholipase A1gamma (iPLA1gamma) is a novel factor involved in coat protein complex I- and Rab6-independent retrograde transport between the endoplasmic reticulum and the Golgi complex. J Biol Chem 284: 26620-26630, 2009.
19. Martinez O, Antony C, Pehau-Arnaudet G, Berger EG, Salamero J and Goud B: GTP-bound forms of rab6 induce the redistribution of Golgi proteins into the endoplasmic reticulum. Proc Natl Acad Sci USA 94: 1828-1833, 1997.

20. Martinez O, Schmidt A, Salaméro J, Hoflack B, Roa M and Goud B: The small GTP-binding protein rab6 functions in intra-Golgi transport. J Cell Biol 127: 1575-1588, 1994.

21. Tian $\mathrm{K}$, Wang $\mathrm{Y}$ and $\mathrm{Xu} \mathrm{H}$ : WTH3 is a direct target of the p53 protein. Br J Cancer 96: 1579-1586, 2007.

22. Tian K, Jurukovski V Yuan L and Shan J and Xu H: WTH3, which encodes a small $\mathrm{G}$ protein, is differentially regulated in multidrug-resistant and sensitive MCF7 cells. Cancer Res 65: 7421-7428, 2005

23. Perlikos F, Harrington KJ and Syrigos KN: Key molecular mechanisms in lung cancer invasion and metastasis: a comprehensive review. Crit Rev Oncol Hematol 87: 1-11, 2013.

24. Patruno A, Pesce M, Marrone A, Speranza L, Grilli A, De Lutiis MA, Felaco M and Reale M: Activity of matrix metallo proteinases (MMPs) and the tissue inhibitor of MMP (TIMP)-1 in electromagnetic field-exposed THP-1 cells. J Cell Physiol 227: 2767-2774, 2012.

25. Yang K, Palm J, König J, Seeland U, Rosenkranz S, Feiden W, Rübe $\mathrm{C}$ and Rübe CE: Matrix-Metallo-Proteinases and their tissue inhibitors in radiation-induced lung injury. Int J Radiat Biol 83: 665-676, 2007.

26. Iwata H, Yamamoto M, Nemori R, Mizutani M, Iwase T, Miura S, Obata Y, Hara Y, Omoto Y, Toyama T, Yamashita H, Iwase H and Kobayashi S: Localization of gelatinolytic activity can be detected in breast cancer tissues by film in situ zymography. Breast Cancer 8: 111-115, 2001.

27. Kurizaki T, Toi M and Tominaga T: Relationship between matrix metalloproteinase expression and tumor angiogenesis in human breast carcinoma. Oncol Rep 5: 673-677, 1998.

28. Jezierska A and Motyl T: Matrix metalloproteinase-2 involvement in breast cancer progression: a mini-review. Med Sci Monit 15: RA32-RA40, 2009.

29. Brummer O, Athar S, Riethdorf L, Löning T and Herbst H: Matrix-metalloproteinases 1,2, and 3 and their tissue inhibitors 1 and 2 in benign and malignant breast lesions: an in situ hybridization study. Virchows Arch 435: 566-73, 1999. 